\title{
ОТ СОЦИАЛИЗАЦИИ К ДЕСОЦИАЛИЗАЦИИ ПОДРОСТКОВ: ФАКТОРЫ АСОЦИАЛЬНОГО ПОВЕДЕНИЯ
}

\section{FROM SOCIALIZATION TO DESOCIALIZATION OF ADOLESCENTS: FACTORS OF ASOCIAL BEHAVIOR}

\section{S. Komissarenko E. Barkova}

Summary: The article poses the problem of asocial behavior of adolescents as a consequence of their desocialization. In turn, the authors of the article consider desocialization in the form of deformation processes of socialization, when its dominant institutions - the family and school - do not fully realize the educational resource. The asocial behavior of adolescents is largely formed under the influence of a number of factors, among which socio-economic, socio-cultural and informational ones act as priorities. The asociality of adolescents manifests itself in many deviation forms, where aggression is directed not only at the communities of peers, but also at adults, first of all - educators and teachers. It is possible to change the asocial behavior of adolescents if society takes responsibility for controlling the results of productive socialization in Russian society.

Keywords: socialization, upbringing, desocialization, asociality, behavior, adolescents.
Комиссаренко Светлана Сергеевна

Д.культурологии, дочент, Санкт-Петербургский Гуманитарный университет профсоюзов; почетный работник высшего образования России

komissarenko07@mail.ru

Баркова Екатерина Валериевна

К.ф.н., доцент, Санкт-Петербургский Гуманитарный университет профсоюзов barkova_katya@bk.ru

Аннотация: В статье поставлена проблема асоциального поведения подростков как следствия их десоциализации. В свою очередь, авторы статьи рассматривают десоциализацию в виде деформационных процессов социализации, когда доминирующие ее институты — семья и школа не реализуют в полной мере воспитательный ресурс. Асоциальное поведение подростков во многом формируется под влиянием ряда факторов, среди которых социально-экономические, социально-культурные и информационные выступают как приоритетные. Асоциальность подростков проявляется во многих девиационных формах, где агрессия направлена не только на сообщества сверстников, но и взрослых, прежде всего, - преподавателей, воспитателей и учителей. Изменить асоциальное поведение подростков можно при условии, если общество возьмет на себя ответственность за контроль над результатами продуктивной социализации в российском обществе.

Ключевые слова: социализация, воспитание, десоциализация, асоциальность, поведение, подростки.

детей и подростков в социум путем освоения социокультурных паттернов, деструктуризируется и модифицируется. Во многом это происходит из-за нарушения иерархитизации влияния агентов социализации на развитие подростка. Семья как первичный институт с его агентами - родителями, близкими родственниками и друзьями перестают быть для подростков идентификационными объектами и референтными личностями, так же как и педагоги, преподаватели и воспитатели образовательных учреждений. Во многом они утрачивают свои приоритетные позиции под воздействием интернет-технологий. Сегодня интернет стал одним из ведущих институтов социализации и его влияние на развитие личности подростка становится огромным. Информационное общество, столь стремительно заявившее о себе в конце XX столетия, привело к массовой компьютеризации, следствием чего информационно-цифровые технологии стали наиболее мощным инструментом детской и подростковой социализации. Интернет-технологии, состоящие из разнообразных сайтов, чатов, форумов и социальных сетей, активно завладели умами подрастающего поколения. Цифровой мир изменил поведение подростков, в котором наравне с получаемой необходимой образовательной информацией, им открылся доступ к много- 
образным сайтам, несущим асоциальные идеи. Фактор информационного воздействия свидетельствует о том, что в этом новом мире подростки становятся не только потребителями той или иной опасной информации, но и сами начинают «творить» свой мир, о котором мало что знают как педагоги, так и их родители. В информационно-коммуникативном пространстве они обретают ту субъектность, которая не является значимой ни для школы, ни для семьи. Сегодня традиционная педагогическая формула субъектно-объектных отношений не теряет своей воспитательной значимости и никак не пересматривается, несмотря на актуальный запрос педагогических практик.

Интернет, обладая неограниченными возможностями, во многом опережает по влиянию традиционные институты социализации - школу и семью. Однако несмотря на современные реалии информационного общества эти институты по-прежнему обладают огромным потенциалом воздействия на подростков и на их социализацию.

Вопросы социализации подростков становились научными темами многих представителей социальногуманитарной мысли: педагогов, психологов, философов и социологов и др.: Л.С. Выготского, В.М. Бехтерева, А.С. Макаренко, А.А. Реана, И.С. Кона, А.В. Мудрика, А.В. Лисовского, Д.И. Фельдштейна, Е.В. Змановской, А.А. Сукало, Э Дюркгейма, Т. Парсонса, Э. Фромма, К. Роджерса, Г. Гидденса, Ф. Гиддингса, Н. Смелзера, Э. Эриксона, 3. Фрейда, А. Адлера, А. Маслоу, и мн. др.

Социальность можно рассматривать в виде результата социализации, представляющего собой процесс социального научения. В ходе социализации детей и подростков вырабатываются их социальные качества и черты, способствующие эффективному встраиванию в жизнь социума. Ее институты обеспечивают благоприятные условия для данного встраивания. Социализация всегда целенаправлена на тот образ личности, который задается обществом, будь оно первобытное или постиндустриальное. Универсальность социализации как социально-педагогического явления заключается в ее всеохватывающей направленности на любого члена общества с тем, что он должен овладеть законами совместного не только существования, но и взаимодействия. Овладение законами совместного проживания требуют знаний норм как образцов и правил данного проживания.

Поэтому в структуре социализации категории «норма» принадлежит доминирующая роль. Нормативность обеспечивает порядок во взаимодействии и осмысленность во взаимоотношениях. Она отвечает за предсказуемость поведения того или члена общества и устраняет неопределенность во взаимоотношениях. За нарушение социальных норм следуют те или иные санкции. Бинар- ность проявления нормативности можно сформулировать постулатами: «можно» - «нельзя»; «дозволено» - «недозволено» и т.д.

Категория «ценностей» обеспечивает ориентиры социализации на «идеализированные объекты» и могут выступать в виде идей, идеалов, наделенных, по мнению М.С. Кагана, различного уровня «оценками» и «смыслами». Иерархитизация ценностей рассматривается в соответствии с их носителями: конкретного человека индивидом, личностью; небольших контактных групп; больших неконтактных социальных групп, а также «человечества в целом» $[1$, с. 53, 89]. С позиции социализации как процесса овладения ценностями, интересным представляется мнение М.С. Кагана о концепции «ценностных ориентаций» социолога В. Ядова в контексте изучения мотивации поведения личности. М.С. Каган свое мнение высказал так: «необходимо отличать те специфические мотивы, которые и именуются «ценностями», от иных, управляющих поведением человека <...> это важно <...> для эффективного воспитания саморегулирующего поведения личности; поэтому не только «норма» есть нечто сущностно отличное от «ценности», но и «цель», и тем более «средство», и даже «идеал», которому нужно из отвлеченного представления о желанном будущем стать твоей собственной, личной, переживаемой ориентацией поведения, чтобы функционировать как ценность» [там же, с. 38]. Следовательно, ценностно-нормативная ориентация может быть продуктивной только при условии ее интериоризации.

Такой компонент социализации как «роли», означающий определенные модели нормативного поведения, обеспечивает освоение детьми и подростками окружающей действительности. Детско-подростковые роли постоянно меняются в зависимости от периодов их жизни, начиная с раннего детства и заканчивая ролями школьного возраста. В социализации роли «играются» не только в настоящем, но и служат определенным ориентиром для выбора различных ролевых амплуа в будущем.

Рассматривая общество с позиции структурнофункционального подхода, Т. Парсонс обосновывает «взаимопроникновение» и «взаимообмен» между различными подсистемами общества; культурными, личностными, социальными и поведенческими для того, «чтобы достичь стабильной институционализации, коллективы и роли должны «руководствоваться» конкретными ценностями и нормами, а сами ценности и нормы институционализируются только постольку, поскольку они «воплощаются в жизнь» конкретными коллективами и ролями» $[2$, с. 19].

Социализация сущностно неотделима от культуры, ибо «культура - цемент здания общественной жизни. И не только потому, что она передается от одного чело- 
века к другому в процессе социализации и контактов с другими культурами, но также потому, что формирует у людей чувство принадлежности» [3, с. 48]. Социокультурный контекст социализации раскрывает ее сущность с позиции освоения правил социального порядка в сетке культурных координат общества. Культура в отношении детей и подростков выполняет функцию идентификации, где родителя, близкие и родные становятся объектами для подражания в раннем детстве. Культура проникает в жизнь ребенка через родной язык, символы общения, семейный уклад, традиции времяпрепровождения, игру. Она создает среду взросления, основываясь на отечественные педагогические традиции, в которых личность учителя обладала общественно-значимым статусом. Образу учителя и «учительскому искусству» были посвящены труды К.Д. Ушинского, Л.Н. Толстого, Д.С. Лихачева, В.А. Сухомлинского и др.

Культура - это передача, сохранение и трансляция социально-культурного опыта, представляющего собой сумму накопленных способов бытия в соответствии с национально-культурными смыслами жизни. Это особое восприятие самой жизни, где культурные базовые представления отражают ментальный пласт отечественной культуры. Как пишет Д.И. Фельдштейн «социализация - процесс усвоения и воспроизводства социального опыта и культуры, формирование индивидуальной системы нормативной регуляции и структуры личности» [4, с. 188].

А.В. Мудрик так же определяет сущность социализации в контексте культуры, которая «сводится к тому, что в процессе и в результате социализации человек принимает, усваивает интериоризирует социальные нормы, ценности, поведенческие матрицы, жизненные сценарии, одобряемые или навязываемые культурой того общества, в котором он живет [5, с. 13].

Социализация, как многоаспектное явление, может рассматриваться с разных позиций. Н. Смелзер, анализируя понятие «социализация» использует следующие подходы: адаптивистский (Э. Дюркгейм, Т. Парсонс, Дж. Клаузен); интеракционистский (Ч. Кули, Дж. Мид); психоаналитический (3. Фрейд); когнитивистский (Ж. Пиаже); нравственно-этический (Л. Колберг). Сущность социализации, по мнению ученого заключается в том, что «социализация, т.е. пути, которыми люди приобретают опыт и осваивают установки, соответствующие их социальным ролям, имеют две цели: способствовать нашей интеракции на основе социальных ролей и обеспечить сохранение общества благодаря усвоению его новыми членами сложившихся в нем убеждений и образцов поведения» $[6$, с. 126].

В контексте изучения социализации ученые коррелируют ее социальное предназначение с воспитанием. В связи с этим заслуживающим внимания представляется взгляд Э. Фромма на воспитание, без которого социальное развитие в «раннем детстве» и «подростковом возрасте» невозможно. Ученый рассматривал воспитание «как средство для преобразования социальных запросов в личные качества людей» [7, с. 351]. Э. Фромм определял воспитание с точки зрения социального развития, где «роль воспитания состоит в подготовке индивидуума к выполнению тех функций, которые на него возложены обществом. Иными словами, воспитательный процесс должен сформировать его характер таким образом, чтобы он как можно ближе подходил к социальному характеру, чтобы его личные цели и устремления не конфликтовали с обязанностями, обусловленными его социальным статусом» [там же].

Так же не отделяет социализацию от воспитания Э. Дюргкейм. Социолог подчеркивает, что «общество может существовать только тогда, когда между его членами существует достаточная степень однородности. Воспитание воспроизводит и укрепляет эту однородность, изначально закладывая в душе ребенка главные сходства, которых требует коллективное существование. Но, с другой стороны, без известного разнообразия любая кооперация была бы невозможна. Воспитание обеспечивает сохранение этого необходимого разнообразия; при этом само оно дифференцируется и специализируется. Стало быть, в обоих своих аспектах оно состоит в целенаправленной социализации молодого человека» [8, с. 254].

Следовательно, социализация «покрывает» жизненное пространство подростка в виде целенаправленного процесса, ориентированного на освоение социального опыта, ролей, норм, навыков и ценностей социума.

Понятие «десоциализация» противоположно значению «социализация» и связано с утратой подростками мотивации воспринимать социальный опыт, осваивать социальные роли и ценности, а также следовать заданным обществом образцам и нормам поведения. Десоциализацию можно определить как «неудавшуюся социализацию» (Н. Смелзер). Так же десоциализация может быть обозначена в виде незавершенной социализации или ее деформации. Процессы десоциализации подростков связаны в первую очередь с тем, что признанные институты социализации не справляются со своим предназначением, а ее агенты утрачивают референтность для них. Отсюда проявление асоциального поведения как следствия их десоциализации.

Подростки как объект психолого-педагогических исследований рассматривались в трудах П.Я. Гальперина, Д.Б. Эльконина, Л.И. Божович, Л.С. Выготского. В.В. Абраменковой, А.В. Петровского. С.И Кона, В.С. Мухиной, М. Мид, Э. Эриксона и мн. др. 
Подростковый возраст обозначается в возрастной психологии как особенно сложный, ибо он связан, по выражению Л.С. Выготского, с «трагической эпохой» в их становлении и развитии. Ученый замечает, что «перелом заметен решительно во всем: в изменении голоса, лица, строения тела, когда все члены, по выражению Рубинштейна, находятся в тесном соотношении, как бы на перепутье: они покинули стадию детской цельности и еще не успели установить твердо сплоченной гармонии созревшего тела» [9, с. 247].

Л.С. Выготский подчеркивает, что этот период сопряжен с «чрезвычайно повышенной возбудимостью и неловкостью, т.е. как бы постоянным сознанием своей неприспособленности к среде. Поэтому он в полном смысле слова критический возраст» [там же].

И.С. Кон исследует поведенческие модели подростка, содержащие конфликтные ситуации в его взаимодействии как со сверстниками, так и между собой. В частности, ученый пишет: «его отношения со старшими и сверстниками начинают строиться по типу отношений взрослых, он усваивает систему «взрослых» социальных норм, в отличие от норм, которые установлены взрослыми для детей. Эта ломка старой структуры отношений и становление новой часто порождает конфликтные моменты в отношениях между подростком и взрослыми <...> в естественных условиях такие конфликты неизбежны, так как и потребности подростка и социальные ожидания на его счет довольно противоречивы (уже не ребенок, но еще и не взрослый) [10, с. 142].

Подростковый возраст наиболее восприимчив к тем социальным проблемам, которые сложились сегодня в России. Десоциализация подростков обусловлена прежде всего теми кризисными явлениями, которые свидетельствуют о том, что общество не выработало фундаментальные ценности, объединяющие его членов в «коллективное существование» (Э. Дюркгейм). Аксиологический кризис российского общества проявляется в доминировании ценностей гедонизма, успеха, силы и личного обогащения за счет других. Труд перестал быть ценностью на уровне общественного сознания. Он ушел из ценностного поля нашего социума, а отсутствие социально-значимых идеалов, идей и авторитетных личностей, ценных для подростков, заменяется квази-объектами для подражания. Идеалы соотносятся с красивой и богатой жизнью, где референтными личностями становятся удачливые и везучие люди.

Фактор аксиологического кризиса современного российского общества негативно влияет на подрастающее поколение. Десоциализация есть процесс сущностно конфликтологический, потому что в нем осуществляется противоречие между требованиями обществом освоение заданных паттернов и индивидуальными устремлениями самого подростка, игнорирующего это освоение. Десоциализация связана с утратой или деформацией передачи социокультурного опыта, его отторжением, а также неприятием подростком навязанных ему ролей и декларируемых ценностей, которые носят в обществе двойной стандарт. Социально-культурные факторы соотносятся с мнением Б. Скиннера относительно того, что «молодые люди бросают школу, отказываются идти работать и общаются лишь со своими сверстниками не потому, что чувствуют отчуждение, а потому, что порочным является социальное окружение в семьях, школах, на заводах и в прочих местах. Окружение не только тычет и хлещет, оно отбирает. Теперь стало ясно: мы должны учитывать, что делает с организмом окружение не только прежде, но и после того, как он совершает отклик. Поведение оформляется и поддерживается своими последствиями» $[11$, с. 20].

Семья как основной институт социализации утрачивает свое влияние и теряет авторитет у подростков во многом под влиянием социально-экономических факторов. Социальная дифференциация российского общества на бедных, состоятельных и богатых демонстрирует резкое расслоение в образах жизни. Это расслоение отражается прежде всего на подростках. Все больше семей становятся экономически неблагополучными и социально уязвленными. Они не могут обеспечить подростку качество жизни и удовлетворить его потребности, которые формируются у него во многом под влиянием сравнения с другими, более благополучными семьями. Чувствуя себя ущемленными, подростки выбирают асоциальное поведение в виде некого протеста, несогласия и сопротивления. Семья так же утрачивает воспитательную функцию, ибо нарушено общение. Разговор как его основная форма теряет свою востребованность. Подросток уходит от общения и ограничивается информационно-цифровой средой. Интернет становится тем пространством, где подростки удовлетворяют свои коммуникативные потребности и самоутверждаются в интернет-сообществах согласно своей субъектности, что выражается в обеспечении индивидуальных запросов и интересов. Посредством цифровой коммуникации подросток проявляет свою индивидуальность, осваивая роли и нормы интернет-сообществ.

Если семья неблагополучная, то она умножает сложности социализации, трансформируя ее в десоциализацию. Такие семьи не только не создает элементарных условий социального развития подростков, но и устраняются от создания условий для формирования здорового образа жизни детей. Школа вопросами воспитания не может эффективно заниматься в силу того, что она перегружена образовательными процессами и диалог педагогов с родителями не носит продуктивного и систематического характера. 
Десоциализация так же сложна и многомерна, как и социализация. Вместе с тем, она драматичнее и конфликтнее, чем процесс социализации. С одной стороны, процессы десоциализации порождают стрессы, дезадаптацию, социальную отчужденность и изолированность подростка от внешнего мира. Уход в виртуальную реальность ограждает их от мира действительности, отчуждает от общения с родными и близкими. А с другой стороны, подростки могут реализовывать себя через асоциальное поведение. Асоциальность имеет различный вектор направленности: от обычного нарушения учебных норм в образовательном учреждении до правонарушений; от деструктивного поведения и его аддитивных моделей. «Всякому воспитателю приходится сталкиваться с моральными проступками детей, причем проступки эти размещаются на чрезвычайно большой шкале - от легких и незаметных провинностей до настоящих и страшных преступлений, вроде убийств, поджогов и т.п. Точно так же и меры воздействия, принимаемые педагогами против таких детей, начинаются с легких и простых выговоров и кончаются колониями для малолетних преступников, где детей держат за решеткой и применяют к ним тюремный режим» [12, с. 260].

Асоциальное поведение включает в себя такое понятие как «девиация», характеризующаяся отклонением поведения от общепринятых норм взаимодействия. Девиация может быть как позитивной, так и негативной. Позитивные девиации, связанны с самоутверждением личности подростка, проявлением одаренности и даже гениальности. Асоциальность опирается на негативную девиацию, которая проявляется у подростков не только в отклоняющимся поведении от общепринятых социокультурных норм и правил, но и как сознательное их игнорирование и нарушение. Она имеет крайние формы отклонений от здорового образа жизни, связанных с наркоманией, алкоголизмом, проституцией. По мнению исследователя Е.В. Змановской, девиации различаются по устойчивости. Они могут быть временными, преходящими, устойчивыми, стойкими. «Они также могут быть обратимыми и необратимыми. Примерам преходящих девиаций являются разнообразные подростковые реакции, отражающие кризисный характер данного возрастного периода и существенно осложняющие жизнь как самим подросткам, так и окружающим людям» [13, с. 16-17].

Э. Гидденс пишет о девиации следующее: «термином «девиантное поведение» называют поступки, которые нарушают общепринятые нормы. То, что признается «девиантным» может быть различным в разное время и в разных местах: «нормальное поведение» в условиях одной культуры может быть признанно «девиантным» в другой культуре. Понятие «девиация» шире понятия «преступления». Последнее относится к некомфортному поведению, при котором нарушается закон» [14, с. 214].
Разнообразные модели девиантного поведения зависят от социализации личности ребенка и являются следствием его десоциализации в подростковом возрасте.

Наиболее критическими формами асоциального поведения являются те, что связаны с проявлением агрессии. А.А. Реан под агрессией понимает намеренные действия, которые направлены на причинение ущерба другому человеку, группе людей или животному. При этом, он отмечает, что такое понятие как «агрессивность» отлично от понятия «агрессия» (несинонимично). Под агрессивностью ученый понимает «свойство личности, выражающееся в готовности к агрессии» [15, с. 133-134]. В своем исследовании подростковой агрессии А.А. Реан исходит из первого подхода, который он обозначил как этико-гуманистический. Его сущность связана с причинением вреда другому человеку как зло, как поведение, противоречащее позитивной сущности человека. Представителями данного похода могут выступать теории и концепции психологов-гуманистов К. Роджерса, А. Маслоу, В. Франка. Манифестом гуманистической психологии» А.А. Реан провозглашает идеи Э. Фромма о «развертывание сил человека согласно законам его природы» [там же, с. 141].

Когнитивно-бихевиоральный подход к исследованию агрессии основывается на теории социального научения А. Бандуры. Когнитивная составляющая научения обеспечивает способность человеку «предвидеть отдаленные последствия и переносить их на текущее поведение помогает выработке «предусмотрительного поведения». Это достигается, пишет А. Бандура, «путем обеспечения человека стимулами и подкрепляющими мотивами для осуществления определенных действий» [16, с. 35]. Источник агрессии, по мнению ученого, находится в «дегуманизации поведения», следствием которого является «дегуманизация жертвы». Так, ученый пишет, что «анализ когнитивных обстоятельств, сопутствующих наказуемому поведению, показывает, что дегуманизация способствует выработке различных маневров для самооправдания агрессии» [там же, с.218].

Подростки склонны направлять свою агрессию на взрослых, на аутсайдеров в группе или представителей других групп (соседских, дворовых, ученических сообществ). Подростковая агрессия может приобретать черты жестокости, ненависти и враждебности. Э. Фромм писал, что любая внешняя угроза личным интересам (материальным или эмоциональным) порождает тревогу (К. Хорни), а самая естественная реакция на нее - проявление крайне враждебности. «В некоторых моментах такая угроза ассоциируется с определенными людьми, и тогда, в этом случае орудие разрушительности оборачивается против них» [17, с. 229]. В подростковой среде часто агрессия проявляется в раз- 
рушительности. «Разрушительность - это продукт непрожитой жизни. Различные условия, индивидуальные или же социальные, которые подавляют стремление к жизни, порождают страсть к разрушению, наполняющую своего рода резервуар, откуда вытекают всевозможные разрушительные тенденции - по отношению к другим и к себе» [там же].

Так же подростковая асоциальность проявляется речевой агрессии в виде плохо контролируемой ситуации коммуникативного взаимодействия, которая направлена на нанесение вербального (словесного или письменного) или невербального (жест, поза) ущерба (оскорбление человеческого достоинства, проявление неуважения, демонстративное проявление силы или угрозы) с целью доказать свое превосходство с использованием враждебной лексики.
Таким образом, асоциальное поведение подростков является лишь следствием их десоциализации, которая, в свою очередь, есть результат деформационных процессов социализации. Социально-экономические, социально-культурные и информационные факторы, а также кризисные явления российского общества приводят к тому, что поведение подростков носит асоциальный и, к сожалению, систематический характер. В связи с этим возникает проблема ответственности самого общества, а также его основных институтов за воспитание и полноценную социализацию. Пока эта ответственность не будет осознана и принята обществом как социальный факт, асоциальность подростков не будет снижаться. «Бесспорна та истина, что нет ничего в социальной жизни, чего не было бы в индивидуальных сознаниях; но почти все, что в них находится, взято ими у общества» [18, с. 359].

\section{ЛИТЕРАТУРА}

1. Каган М.С. Философская теория ценности - СПб: Т00 ТК «Петрополис». - 205 с.

2. Парсонс Т. Система современных обществ / Пер. с англ. Л.А. Седова, А.Д. Ковалева. — М.: Аспект-Пресс, 1997. — 270 с.

3. Смелзер Н. Социология /Пер. с анг. - М.: Феникс, 1994. - 688 с.

4. Фельдштейн Д.И. Психология становления личности- М.: Международная педагогическая академия, 1994. - 202 с.

5. Мудрик А.В. Социальная педагогика: Учебное пособие -2-е изд., М.: Издательский центр «Академия», 2013. - 240 с

6. Смелзер Н. Социология /Пер. с анг. - М.: Феникс, 1994. - 688 с.

7. Фромм Э. Бегство от свободы: Человек для себя /Пер. с анг. Д.Н. Дудинской. - Мн.: 000 «Попурри», 1998.- 672 с.

8. Дюркгейм э. Социология. Ее предмет, метод, предназначение /Пер. с фр, состав., послесл. и прим. А. Б. Гофмана. - М.: Канон, 1995. - 352 с.

9. Выготский Л.С. Педагогическая психология /Под ред. В. Давыдова. - М.: Изд-во АСТ, 2004. - 512 с.

10. Кон И.С. Социология личности - М. : Политиздат, 1967. - 383 с.

11. Скиннер Б.Ф. Технология поведения /Американская мысль: [Тексты]; /Под ред. В.И. Добренькова. - М. : Издательство МГУ, 1994. - С. 16-24

12. Выготский Л.С. Педагогическая психология /Под ред. В. Давыдова. - М.: Изд-во АСТ, 2004. - 512 с.

13. Змановская Е.В., Рыбников В.Ю. Девиантное поведение личности и группы: Учебное пособие. - СПб: Питер, 2012. - 352 с.

14. Гидденс Э. Социология /Пер. с анг. // При участии К. Бердсолл. Издание 2-е, полностью перераб. и дополн. - Москва : Едиториал УРСС, 2005. - 632 с.

15. Реан А.А. Психология личности. — СПб.: Питер, 2013. — 288 с.

16. Бандура А. Теория социального научения. - СПб.: Евразия, 2000. - 320 с.

17. Фромм Э. Бегство от свободы: Человек для себя /Пер. с анг. Д.Н. Дудинской. - Мн.: 000 «Попурри», 1998.- 672 с.

18. Дюркгейм Э.0 разделении общественного труда /Пер. с фр. А.Б. Гофмана, прим. В.В. Сапова - Москва: Канон, 1996. - 432 с. 